\title{
QUANTOS SUJEITOS DEVEM PARTICIPAR DA PESQUISA? O SUJEITO REIVINDICATIVO COMO POSSIBILIDADE NA PESQUISA EM EDUCAÇÃO
}

\author{
¿CUÁNTOS SUJETOS DEBEN PARTICIPAR EN LA INVESTIGACIÓN? EL SUJETO \\ RECLAMANTE COMO POSIBILIDAD EN LA INVESTIGACIÓN EDUCATIVA
}

HOW MANY SUBJECTS SHOULD PARTICIPATE IN THE RESEARCH? THE CLAIMING SUBJECT AS A POSSIBILITY IN EDUCATIONAL RESEARCH

\author{
Otavio Henrique Ferreira da SILVA ${ }^{1}$ \\ Ademilson de Sousa SOARES ${ }^{2}$
}

RESUMO: Este texto tem como objetivo apresentar um importante componente a compor o método das pesquisas qualitativas em educação: o sujeito reivindicativo. Ao planejar a estrutura de uma pesquisa, os pesquisadores podem ter dúvidas quanto à definição do número adequado de sujeitos participantes. O sujeito reivindicativo na pesquisa em educação faz um movimento diferente do que tradicionalmente se faz. Ao invés do pesquisador solicitar, é o sujeito que reivindica a participação na pesquisa. É apontado que a relação pesquisadorsujeito e sujeito-pesquisador precisa de maiores aprofundamentos, e que os pesquisadores em educação precisam ter como pressuposto a possibilidade de se depararem com outros sujeitos no campo de pesquisa, que podem trazer importantes contribuições para seus estudos.

PALAVRAS-CHAVE: Sujeito reivindicativo. Pesquisa democrática. Metodologia de pesquisa.

RESUMEN: Este texto tiene como objetivo presentar un componente importante de un método para la investigación cualitativa en educación: el sujeto reclamante. Al planificar la estructura de una investigación, los investigadores pueden tener dudas sobre la definición del número apropiado de sujetos participantes. El sujeto reclamante en investigación en educación hace un movimiento diferente de lo que tradicionalmente se hace. En lugar de que el investigador pregunte, es el sujeto quien dice participar en la investigación. Se señala que la relación investigador-sujeto y sujeto-investigador necesita más estudio y que los investigadores en educación deben tener como un supuesto, la posibilidad de encontrar otros temas en el campo de la investigación que puedan aportar importantes contribuciones a sus estudios.

PALABRAS CLAVE: El sujeto reclamante. Investigación democrática. Metodología de investigación.

\footnotetext{
${ }^{1}$ Universidade Federal de Minas Gerais (UFMG), Belo Horizonte - MG - Brasil. Doutorando no programa de Pós-Graduação em Educação. ORCID: https://orcid.org/0000-0002-2754-4783. E-mail: hotaferreira@gmail.com ${ }^{2}$ Universidade Federal de Minas Gerais (UFMG), Belo Horizonte - MG - Brasil. Professor da Faculdade de Educação. Doutorado em Educação (UFMG). ORCID: https://orcid.org/0000-0002-4056-1203. E-mail: pacosoares65@gmail.com
} 
ABSTRACT: This text aims to present an important component of method for qualitative research in education: the claiming subject. When planning the structure of a research, researchers may have doubts about the definition of the appropriate number of participating subjects. The claiming subject in research in education makes a different move from what is traditionally done. Instead of the researcher asking, it is the subject who claims to participate in the research. It is pointed out that the researcher-subject and subject-researcher relationship needs further study and that researchers in education need to have as an assumption, the possibility of encountering other subjects in the field of research that can bring important contributions to their studies.

KEYWORDS: Claiming subject. Democracy research. Methodological research.

\section{Introdução ${ }^{3}$}

Mostro como algumas inspirações, que podem vir de qualquer coisa e lugar e em (PARAÍSO, 2012).

Este artigo apresenta reflexões e dialoga com o movimento que tem buscado criar alternativas no modo de fazer pesquisa; um exemplo são as metodologias interativas, democráticas e participativas na produção de pesquisas em educação. Temos como objetivo, ao partilharmos nossas reflexões neste texto, apresentar um importante componente a compor o método das pesquisas qualitativas em educação: o sujeito reivindicativo. Isso porque identificamos que o pesquisador pode incluir como sujeitos da pesquisa outros sujeitos que, além de reivindicarem a participação, demonstrem potencial de contribuir com os objetivos da pesquisa.

Inspirados pelos princípios da gestão democrática da educação, nos propusemos a investigar e discutir no Mestrado em Educação e Docência (UFMG) a participação da comunidade escolar na gestão da educação infantil ${ }^{4}$ e, nos dois primeiros semestres (2015), focamos na elaboração do projeto de pesquisa, no processo de avaliação do mesmo pelo Comitê de Ética e Pesquisa da Universidade Federal de Minas Gerais (COEP/UFMG) ${ }^{5}$ e, após obtermos a autorização para realizar a investigação de campo, iniciamos e concluímos a pesquisa, conforme previsto em cronograma e respeitando a legislação brasileira em vigor que

${ }^{3}$ Uma versão deste texto foi apresentada no II Congresso de Inovação e Metodologias de Ensino realizado em 2016 na Universidade Federal de Minas Gerais, Belo Horizonte/MG. Para esta versão, foram realizadas revisões e pequenos acréscimos no corpo do texto.

${ }^{4}$ Todo o percurso de mestrado, incluindo disciplinas e pesquisas teóricas e empíricas, foi iniciado e concluído entre os anos de 2015 e 2016.

${ }^{5}$ A pesquisa de campo foi aprovada e autorizada pelo COEP/UFMG e registrada sob o $\mathrm{n}^{\circ} 49227515.0 .0000 .5149$ na Plataforma Brasil. Todos os sujeitos participantes estavam de acordo e assinaram o Termo de Consentimento Livre e Esclarecido (TCLE).

RIAEE - Revista Ibero-Americana de Estudos em Educação, Araraquara, v. 16, n. 4, p. 2395-2409, out./dez. 2021. e-ISSN: 1982-5587 
estabelece, através das Resoluções 196/96, 466/12 e 510/16, as pesquisas com humanos (BRASIL, 1996; 2012; 2016).

Em nosso planejamento e durante todo o processo de pesquisa procuramos utilizar abordagens metodológicas que nos permitissem ter uma relação democrática com os sujeitos. Porém, fazer escolhas democráticas na pesquisa em educação toca em questões consideradas fundamentais ao se pesquisar na área de ciências humanas e sociais.

Quando investigamos a sociedade humana, estamos lidando com um objeto que é dinâmico, não estático, não livre de modificações, pois o que é humano tem o presente marcado pelo passado e pensado para o futuro, o que é humano é histórico (MINAYO, 1994).

Também, na pesquisa com seres humanos o rigor ético e o compromisso social são essenciais ao pesquisador (FLICK, 2009). Este deve se preocupar com o respeito ao sujeito da pesquisa e em proporcionar retornos sobre os achados às pessoas que se propuseram a participar do estudo. A preocupação com o rigor ético em pesquisas que envolvem crianças, como a nossa, por exemplo, deve ser ainda maior, como afirma Sônia Kramer (2002).

Acreditamos que não seria ético com os sujeitos e com os nossos princípios usarmos técnicas e métodos que não fossem democráticos, pois, afinal, pretendíamos ouvir os sujeitos da comunidade escolar de determinadas instituições de educação infantil no município de Betim/MG.

$\mathrm{Na}$ dialética entre o arcabouço democrático que orientou o estudo e as incertezas que nos deixam em situação de fragilidades ao se pesquisar na área de ciências humanas e sociais emergiu o sujeito reivindicativo da pesquisa. Não estamos partindo do nada, mas apenas fomentando a discussão sobre uma possibilidade diferente que optamos ao definirmos os sujeitos de nossa pesquisa em educação.

\section{A abordagem metodológica}

Tal como elucida Minayo (1994), nós entendemos a metodologia como o caminho do pensamento e a prática exercida ao logo do percurso. A postura que adotamos ao pesquisar tem seguido dois princípios fundamentais com base em um plano teórico-metodológico influenciado por autores de correntes dialético-marxistas, pois, como nos diz Garcia (2003, p. 35), é preciso encarar o campo da pesquisa como um "[...] momento desafiador a que os intelectuais públicos são chamados a participar se comprometendo com a radicalização da democracia, pondo as suas pesquisas, os seus escritos e as suas falas a serviço de um projeto emancipatório". 
O primeiro dos princípios é o rigor metodológico necessário para se fazer pesquisa. Isso inclui as ações de planejar, refletir, preparar-se para imprevistos, organizar o material, conquistar e obter uma estrutura de recursos físicos e financeiros.

O segundo princípio diz respeito à flexibilidade necessária para realizar investigações no campo das ciências humanas. Carlos Brandão e Maristela Borges (2007, p. 57) nos influenciam porque são coerentes ao dizer que qualquer "[...] modelo de ciência fechado em si mesmo é uma experiência de pensamento fundamentalista, como o de qualquer religião ou qualquer outro sistema de sentido fanático".

Ao lidarmos com pessoas, crianças, famílias, profissionais, gestores, movimentos sociais e outros tantos, estamos cientes de que as coisas não podem ser tão previsíveis, pois estamos condicionados a possíveis variações, mudanças, imprevistos, e não buscamos certezas, mas sim o diálogo.

O desafio em que nos lançamos - até para nós - parece ser ousado, mas necessário ao ponto de vista intelectual, pois estamos fazendo pesquisa democrática e precisamos de caminhos democráticos. O encontro no percurso teórico-exploratório com Uwe Flick (2009, p. 361) nos possibilitou escolher a triangulação como nossa metodologia, pois segundo o autor, essa “[...] palavra-chave é utilizada para designar a combinação de diversos métodos, grupos de estudo, ambientes locais e temporais e perspectivas teóricas distintas para tratar de um fenômeno". Também, ainda conforme o autor, a “[...] triangulação pode ser aplicada como uma abordagem para fundamentar ainda mais o conhecimento obtido por meio dos métodos qualitativos. Fundamentação, aqui, não significa avaliar os resultados, mas ampliar e complementar sistematicamente as possibilidades de produção do conhecimento" (FLICK, p. $362)$.

Utilizamos alguns métodos que são mais tradicionais nas pesquisas, como por exemplo, entrevistas e grupos de discussão, mas a perspectiva do método da bricolagem (KINCHELOE; BERRY, 2007) ampliou nossa visão em relação às escolhas metodológicas: devido ao fato de ser um método dinâmico, a bricolagem permite inovar nos processos de pesquisa em educação. Claro que não adotamos essa perspectiva como o fundamento estrutural de nossa investigação, mas, ao admitirmos a complexidade do objeto da nossa pesquisa, “[...] a bricolagem constrói um papel muitíssimo mais ativo para os seres humanos, tanto ao moldar a realidade quanto ao criar os processos e as narrativas de pesquisa que a representam" (KINCHELOE; BERRY, 2007, p. 16-17).

Desta forma, na coleta de dados triangulamos métodos como: grupos de discussões (WELLER, 2013); entrevistas (TEIXEIRA; PÁDUA, 2006); observação participante (FLICK, 
2009); pesquisa participante (BRANDÃO; BORGES, 2007); e bricolagem (KINCHELOE; BERRY, 2007). Os instrumentos que foram usados para registrar dados e obter informações foram: cadernos de campo, filmagens, gravações de áudios, fotos, questionários abertos sobre a escola, questionário semiestruturados sobre os participantes, desenhos com as crianças, conversas formais e informais.

\section{Sujeito da pesquisa: uma definição inconclusa?}

O questionamento colocado nessa seção não é em relação ao significado do que é sujeito. Claro que o conceito sobre essa palavra não é unânime no meio científico, mas, na nossa concepção, o sujeito “[...] passa a ser, então, aquilo que dele se diz” (PARAÍSO, 2012, p. 29). Antes de falarmos da nossa dúvida, é importante considerar a seguinte contextualização.

Até a conclusão do projeto de pesquisa foram cursadas duas disciplinas do curso de Mestrado em Educação e Docência (UFMG) sobre metodologias de pesquisa e uma sobre os sujeitos da pesquisa. As duas primeiras contribuíram para o amadurecimento dos métodos escolhidos, para o levantamento de referências bibliográficas, e também possibilitou conhecer outras pesquisas e outras propostas metodológicas com a escuta dos colegas de turma. A disciplina sobre os sujeitos ampliou os referenciais e, principalmente, contribuiu para a definição dos sujeitos participantes do estudo. Ao longo desta última disciplina, nossas reflexões giraram no eixo de três duplas perguntas: “Quem é o sujeito? Por quê?”, “Onde ele se encontra? Por quê?", “Quantos são? Por quê?”.

Como a nossa pesquisa teve como temática a participação da comunidade escolar na gestão da educação infantil, logo, estamos falando sobre a comunidade e sobre a gestão da educação. Então, respondendo a primeira pergunta, “Quem é o sujeito?”, em nosso caso, é a comunidade escolar de três instituições de educação infantil e alguns gestores municipais.

E sobre “Onde ele se encontra?", escolhemos o município de Betim/MG e selecionamos inicialmente três Centros Infantis Municipais ${ }^{6}$-CIM's. Quanto aos gestores, a princípio queríamos ouvir pessoas ligadas à Secretaria Municipal de Educação de Betim, ao Sindicato Único dos Trabalhadores em Educação Sub-sede Betim, ao Conselho Municipal de Educação da cidade e, também, as diretoras dos três CIM's.

${ }^{6}$ Essa é a nomenclatura utilizada no município de Betim-MG para identificar as instituições de educação infantil que pertencem à rede pública municipal de educação básica. 
Para responder a terceira pergunta, “Quantos são?”, foi preciso amadurecer o conceito de comunidade escolar. Numa perspectiva ampliada, ela é composta por alunos (crianças na educação infantil), pais, profissionais, lideranças da sociedade civil, sendo pessoas que estão envolvidas diretamente e indiretamente com o ambiente escolar (LOMBARDI, 2013; SILVA, 2015; TEIXEIRA, 2010). Definimos que seriam escolhidos, em cada comunidade escolar, um total de doze sujeitos, sendo três de cada segmento: crianças, pais, profissionais e sociedade civil. E, de gestores, escolheríamos um de cada instituição.

Obviamente, não podemos realizar uma investigação de campo sem definir os sujeitos, pois, conforme citado anteriormente, o sujeito é "aquilo que dele se diz". Mas a nossa dúvida durante a elaboração, e que persistiu até o momento em que finalizamos o projeto de pesquisa, foi em relação à quantidade de sujeitos selecionados para a investigação. Será que foi adequada? Será que realmente era uma amostra representativa? Será que iria nos propiciar resultados importantes para a temática investigada? Será que eram muitos e assim dificultaria o nosso trabalho? Será que seria essa uma quantidade adequada de sujeitos ao propormos conhecer a realidade social das comunidades escolares?

Enfim, não tínhamos clareza se realmente seria a quantidade adequada. Percebemos que, após a finalização da pesquisa de campo, não seria mesmo possível saber um número exato de sujeitos, mas seria possível, apenas, chegar a uma previsão aproximada com a ajuda dos referenciais (conhecimento teórico) e, principalmente, com o auxílio da experiência com a temática (conhecimento empírico).

Isso que estamos fazendo é pesquisa qualitativa, é lidar com as incertezas, é lidar com a dúvida, em outras palavras, como diz Meyer e Paraíso (2012, p. 18), “[...] sabemos que não são poucas as dúvidas metodológicas daqueles/as que se aventuram a investigar sem ter um caminho seguro a percorrer durante esse processo de pesquisar". O que buscamos fazer, ao ponderarmos o número de quarenta e dois sujeitos, foi deixar o mais claro possível os motivos e o porquê de projetarmos tal quantidade.

E de fato a entrada no campo de investigação nos demandou a modificação de algumas estratégias. Um dos três Centros Infantis Municipais demonstrou não ter interesse em nos receber, tentamos, insistimos, o que nos custou tempo, mas não conseguimos adentrar na instituição. Neste caso, optamos por enfatizar a investigação nas outras duas instituições.

A quantidade de gestores foi ampliada, pois, ao longo das entrevistas e dos grupos de discussões, sentimos a necessidade de fazermos a escuta de outros atores importantes para a temática. Como trouxemos para a nossa metodologia contribuições da pesquisa participante (BRANDÃO; BORGES, 2007), os próprios sujeitos nos apontaram outras pessoas a serem 
ouvidas. Terminamos a pesquisa de campo com um total de 39 sujeitos envolvidos, mas o que mais nos chamou atenção, e que nos impulsionou para ampliar e aprofundar essa discussão, foi o que aqui nomeamos de sujeito reivindicativo, como será exposto no tópico a seguir.

\section{O sujeito reivindicativo}

A escolha por uma temática relacionada à democracia, educação democrática, gestão democrática, participação popular e social não necessariamente implica em caminhos metodológicos democráticos e isto nos gera as seguintes indagações: as pesquisas que se propõem a colaborar com a "radicalização da democracia"7 e com um projeto social emancipatório necessariamente requerem caminhos metodológicos democráticos? É possível ser democrático em todos os momentos? Certamente, isso necessita de ser mais aprofundado.

Um conceito básico de democracia é o de que a democracia é "[...] caracterizada por um conjunto de regras (primárias ou fundamentais) que estabelecem quem está autorizado a tomar as decisões coletivas e com quais procedimentos" (BOBBIO, 1986, p. 18). No regime democrático não se pode dizer que todas as pessoas participam, pois mesmo na mais perfeita democracia não se escuta a opinião de todos, mas o que se leva em conta é a maioria, o aproximado do todo. Para que a decisão que é tomada por um cidadão, vários cidadãos ou muitos seja apreciada como coletiva, ela precisa ter como amparo algumas regras, e a decisão daquilo que será levado em conta precisa ser algo real, onde as pessoas tenham condições de fato de tomar decisão (BOBBIO, 1986). Nos estudos que buscam avançar em relação à perspectiva proposta por Bobbio (1986) é importante considerar as reflexões de Costa e Prado (2017) que querem garantir democracia efetiva para grupos sociais subalternos e excluídos.

A relação da nossa pesquisa com a democracia consiste na articulação que fizemos de proporcionar condições para as pessoas participarem do estudo, como por exemplo, a escuta que fizemos desses sujeitos, a postura sensível para aceitar sugestões que emergiram na relação pesquisador-sujeito e a adoção de uma postura aberta para aprender com as novas experiências.

$\mathrm{Na}$ definição de quem seriam os sujeitos da pesquisa, buscamos deixar com que as próprias comunidades e instituições escolhessem os participantes. Claro que algumas vezes tivemos que decidir, pois pesquisar envolve tempo, recursos, acessibilidade, autorização e, na

\footnotetext{
${ }^{7}$ Aqui usamos a expressão radicalização da democracia para designar trabalhos que tragam como objeto de estudo ou como desafio a construção de uma sociedade mais justa, com mais igualdade e reconhecimento das diferenças sociais. Radicalizar a democracia na pesquisa é manter sempre viva a postura democrática tanto do pesquisador, quanto de sua análise, e também das estratégias metodológicas adotadas. Sobre essa problemática, ver Costa e Prado (2017)
} 
pesquisa qualitativa em Ciências Humanas e Sociais, existe também a imprevisibilidade. Sempre tivemos em busca de um caminho ampliado e não de um caminho estreito ou unilateral.

Foram muitas as situações, as experiências, mas, especificamente, o nosso olhar neste texto está voltado para uma das comunidades escolares em que trabalhamos, sendo essa a comunidade do Centro Infantil Municipal Recanto da Criança, localizado no Bairro Petrópolis, em Betim.

Após as conversas iniciais em busca da autorização para a entrada no ambiente escolar, realizamos seis visitas à instituição no total. As visitas ocorreram entre os dias 03,09 , 16, 23, 25 e 26 do mês de novembro de 2015. Durante o mês de outubro já havíamos conversado com uma das gestoras e, como a instituição estava passando por mudanças na direção, no dia 03/11 foi preciso estabelecer outro diálogo com a nova diretora.

Na presente oportunidade e após o consentimento da gestora, solicitamos à mesma que nos ajudasse a convidar pessoas da comunidade para participar de uma reunião de apresentação da pesquisa. A diretora verificou o melhor dia e horário para que pudéssemos retornar ao CIM e convidou algumas pessoas que tinham disponibilidade entre os funcionários, familiares e lideranças comunitárias para participarem do encontro na data marcada. A condição para a participação das crianças em nosso estudo implicava primeiramente na aceitação por parte do responsável, conforme assinala a resolução do Conselho Nacional de Saúde 466 de 12 de dezembro de 2012, no inciso III, relacionado aos aspectos éticos das pesquisas que envolvem humanos:

g) obter consentimento livre e esclarecido do participante da pesquisa e/ou seu representante legal, inclusive nos casos das pesquisas que, por sua natureza, impliquem justificadamente, em consentimento a posteriori (BRASIL, 2012, p. 4).

As atividades de campo foram avançando com a realização dos grupos de discussão, coletas de dados através da observação, registros no caderno de campo e registros fotográficos. Tínhamos liberdade para circular pelo ambiente da instituição, participávamos da rotina em alguns momentos, ajudávamos quando era preciso, mas de certa forma, para algumas pessoas, continuávamos ainda como estranhos, e na relação com outras, o estranhamento já vinha sendo reduzido. Este é um desafio onde "[...] o pesquisador enfrenta a questão da negociação da proximidade e da distância em relação à(s) pessoa(s) estudada(s)" (FLICK, 2009, p. 115).

A redação no caderno de campo do dia $25 / 11$ fez o seguinte registro: 
A minha relação com o grupo já estava sendo mais bem aceita em vista das outras visitas. Pude notar que os olhares voltados para mim já não eram mais tão constantes. Tanto pelos adultos como pelas crianças. Muitas pessoas já se aproximavam de mim, outras ainda pareciam pouco receosas, mas gradativamente o vínculo foi se estabelecendo e a minha presença foi sendo acolhida, de modo a não ser mais uma tão precoce novidade. Constantemente, eu era convidado pelas colegas para lanchar, almoçar, tomar um cafezinho (Notas do caderno de campo, dia 25/11/2015).

As nossas ações, em partes, seguiam alguns roteiros elaborados para a coleta de dados, no entanto, também procuramos manter-nos sensíveis e flexíveis diante do que acontecia no ambiente. A interação era constante com as crianças e com os adultos, mas as pequeninas eram mais desinibidas, perguntavam, questionavam a nossa presença, queriam saber o porquê de nós pesquisadores usarmos câmeras, gravador e caderno. De certa forma, estavam demandando participar da pesquisa, mas não sabiam ainda o como fazer. Poderíamos considerar essas atitudes como características do sujeito reivindicativo, mas tínhamos um foco e fazer pesquisa exige planejamento; dentro disso se inclui a autorização prévia dos sujeitos e ou responsáveis. Também, se registrássemos tudo, poderíamos ficar perdidos na etapa de análise de dados.

$\mathrm{Na}$ quarta e na quinta visita ao CIM já estávamos mais "familiarizados" com o ambiente e com as pessoas, e foram nestes dias que aconteceram interações com algumas pessoas daquela instituição. As interações que aconteciam não foram planejadas e não foram com os sujeitos que a direção havia ajudado a indicar como possíveis participantes do estudo.

Em momentos distintos os sujeitos reivindicativos surgiram em nossa pesquisa na presença de uma cozinheira, de uma criança e de uma professora. Após tomarem conhecimento do motivo pelo qual nos fazíamos presentes no CIM Recanto da Criança, dirigiram-se para nós e começaram a dizer o que pensavam sobre a instituição e sobre a educação infantil. Elas não pediram licença, de fato "entraram na pesquisa". Nossos olhares naqueles dias se concentravam em outros sujeitos, já havíamos realizado alguns registros e levantamento de dados pessoais destes, mas diante do ocorrido, e considerando que estamos fazendo pesquisa qualitativa e democrática, procuramos manter uma postura flexível. Acreditamos que era necessária a inclusão dessas pessoas como sujeitos de nossa pesquisa.

De fato, esses sujeitos reivindicaram o seu lugar, a sua voz, a sua presença em nosso estudo. Em outras palavras, foram direto ao ponto - "olha, é isso que vocês querem saber e é isso o que pensamos". Isso nos faz lembrar Brandão e Borges ao dizerem que:

[...] a relação tradicional de sujeito-objeto, entre investigador-educador e os grupos populares deve ser progressivamente convertida em uma relação do 
tipo sujeito-sujeito, a partir do suposto de que todas as pessoas e todas as culturas são fontes originais de saber. [...] O Conhecimento científico e o popular articulam-se criticamente em um terceiro conhecimento novo e transformador (BRANDÃO; BORGES, 2007, p. 54).

O primeiro fato ocorreu com uma das cozinheiras da escola. No momento não soubemos lidar com a situação: no dia 23/11/2015 ela se aproximou e queria saber informações sobre o que estávamos pesquisando. No dia da realização do grupo de discussão (16/11) com todos os sujeitos da comunidade, ela chegou a ir à sala, entrou, ouviu nossa conversa e depois saiu. Mas foi após esse dia (em 23/11) que percebemos o interesse dela em contribuir com a pesquisa.

Ela veio ao meu encontro e me questionou: "É pesquisa de quê você está fazendo?”. Em sua fala ela foi demonstrando que queria saber mais e também participar da pesquisa. Não estava claro para ela porque algumas pessoas foram escolhidas e outras não. Eu expliquei para ela que solicitei à direção e à coordenação que me ajudassem na escolha das pessoas, pois era impossivel fazer com que todos participassem. Ela concordou com o que eu disse, mas foi acrescentando e dizendo sobre sua experiência na escola. Por questões éticas eu preferi não fazer a gravação. Ela disse que há mais de dezoito anos vive e trabalha naquele local, ela conhece cada pedaço da escola e que se for preciso fazer qualquer trabalho desde a cozinha até direção, ela faz. Segundo ela, a escola antigamente era melhor, antes a relação não era só profissional, as pessoas eram mais unidas e existiam menos diferenças (Notas do caderno de campo, dia 23/11/2015).

$\mathrm{Na}$ visita seguinte, após termos realizado reflexões sobre o fato ocorrido, logo ao chegar à instituição conversamos com a cozinheira e fizemos a ela o convite para nos conceder uma entrevista. Assim, apresentamos o Termo de Consentimento Livre e Esclarecido e comunicamos que seria gravada a conversa.

Na segunda situação, como já tínhamos passado por esta experiência com a cozinheira, caso outras pessoas tivessem posturas parecidas já saberíamos como agir perante a situação. E pela manhã do dia 25/11, durante o horário de recreio, uma criança da turma de 5 anos perguntou-nos sobre o que estávamos fazendo ali no CIM e depois começou a falar um pouco da própria experiência.

Ela perguntou sobre o meu caderno e para que ele servia. Falei que eu estava fazendo pesquisa e que queria conhecer a escola. Ela falou um pouco sobre sua percepção da escola. Disse para mim que o professor dela é muito forte e que durante o ensaio ela teve que beijar a bochecha de um colega, pois fazia parte da coreografia. Perguntei a ela o que ela achava da escola. Ela falou que é legal, mas "só que têm os meninos grandes" (os alunos do primeiro ano). Perguntei se ela era ouvida e ela disse que sim, acrescentando que, antes, quando a outra 
diretora estava na escola, ela ia na secretaria para conversar com a mesma sobre a mãe e o pai dela (Notas do caderno de campo, dia 25/11/2015). Esta criança ainda falou de sua experiência com pesquisas do mundo infantil:

Eu tenho uma pesquisa lá em casa e é sobre borboletas. Eu pego um pote, pego as borboletas e coloco no quadro para ver. Eu vejo as pesquisas de borboletas, porque eu tenho um monte de livros de borboletas. Minhas irmãs têm as receitas de bolos, aí elas me dão uns papéis para anotar borboletas (Criança participante da pesquisa, 2015).

Um dos colegas de sala dessa criança fazia parte do nosso grupo de discussão com a comunidade escolar, assim, ela e outras crianças da turma constantemente nos procuravam para saber mais detalhes sobre a pesquisa e sobre a participação do colega. Não foi só ela que demonstrou interesse em fazer parte do estudo, no entanto, achamos um pouco inviável e fora das condições que possuíamos incluir todas na pesquisa. O grande dificultador em nosso ponto de vista, mas extremamente necessário do ponto de vista ético, é conseguir primeiramente a autorização dos responsáveis pelas crianças para que as mesmas possam colaborar com a investigação. Mas, dentro de nossas limitações, procuramos incluir as pequeninas, solicitando aos responsáveis pela criança relatada acima, que foi uma das primeiras que se aproximou demandando participar de nossas atividades de pesquisa. Tivemos o consentimento dos responsáveis e a criança participou de um grupo de discussão com outras crianças e nos concedeu, também, entrevistas.

O terceiro caso ocorreu no momento que fazíamos registros fotográficos dos espaços da instituição e, ao cumprimentarmos uma professora da turma de 3 anos, começamos a conversar com ela. Nos apresentamos para ela e falamos um pouco sobre o nosso trabalho, a mesma também se apresentou para nós e depois quis saber mais sobre a pesquisa. Ao explicarmos um pouco do trabalho, prontamente ela começou a falar de sua experiência, conforme registrou a nota a seguir.

Ela perguntou o que fazíamos ali, após explicarmos, ela disse que pensou que estivéssemos fotografando a escola para alguma reforma e achou que fôssemos ligados ao setor de obras da prefeitura, pois disse que estávamos olhando muito para as paredes e para o telhado. Depois ela começou a falar um pouco de sua experiencia como professora, disse que havia se formado em processos gerenciais e antes de vir para a educação, trabalhou muito tempo em outra área. Depois que adquiriu certa condição na vida dela, decidiu fazer o que gostava e foi aí que cursou pedagogia e veio trabalhar na educação infantil de Betim. Começou a falar sobre a escola, sobre as crianças, sobre a formação de professores. Foi preciso interrompê-la e fizemos um convite para entrevistá-la (Notas do caderno de campo, dia 25/11/2015). 
A conversa com essa professora nos revelou que nem todas as pessoas que pertenciam ao ambiente escolar sabiam o motivo que nos levava àquele local: a mesma já percebia a nossa presença há alguns dias, mas não sabia ao certo o que procurávamos no CIM. Quando a professora começou a compartilhar informações direcionadas para nossa pesquisa, rapidamente fizemos o convite para ela nos conceder uma entrevista, pois queríamos que a mesma nos autorizasse formalmente para fazermos gravações das conversas.

\section{Considerações finais}

O Sujeito reivindicativo na pesquisa em educação faz um movimento diferente do que tradicionalmente se faz. Ao invés de fazermos solicitação aos sujeitos para a sua participação, é o sujeito que reivindica a participação. Em nosso caso, já havíamos determinado o grupo de sujeitos do Centro Infantil Municipal Recanto da Criança, mas incluímos outras pessoas na medida em que tomaram conhecimento, ou melhor, buscaram conhecer os objetivos da pesquisa e manifestaram o desejo de fazer parte do estudo.

O pesquisador democrático possui objetivos e a intencionalidade é evidente. Não se tem neutralidade científica, entretanto, o campo a ser investigado tem os sujeitos da pesquisa e vários outros sujeitos que compõem o grupo e participam da instituição estudada. Portanto, na medida em que outros sujeitos vão demonstrando interesse em participar e contribuir, como pesquisadores, não podemos nos isentar de ouvi-los.

A pesquisa que é democrática traz como um de seus pilares o compromisso de contribuir com a construção de uma realidade mais justa e mais igualitária. Obviamente, ser a todo momento democrático não é uma tarefa fácil. Nessa pesquisa, nem todas as pessoas que manifestaram interesse puderam participar e serem ouvidas. Por isso, é importante nos preparamos e termos consciência dessa possibilidade. No entanto, foi ao ir a campo que identificamos essa alternativa para o ato de pesquisar, que pode e deve acolher as demandas dos sujeitos reivindicativos.

Os pesquisadores precisam ter como pressuposto a possibilidade de se depararem com outros sujeitos no campo de pesquisa que podem trazer contribuições para os estudos. A nossa escolha por conjugar diferentes métodos e técnicas no levantamento de dados e as estratégias de planejamento e de flexibilidades que traçamos foram importantes para o amadurecimento quanto à necessidade de as pesquisas qualitativas serem mais horizontais, democráticas e construídas em diálogo com os mais diversos sujeitos do campo pesquisado. 
AGRADECIMENTOS: Agradecemos especialmente ao Programa de Mestrado Profissional Educação e Docência (Promestre) pela oportunidade de realizar a presente pesquisa.

\section{REFERÊNCIAS}

BOBBIO, N. O futuro da democracia: uma defesa das regras do jogo. Trad. Marco Aurélio Nogueira. 6. ed. Rio de Janeiro: Paz e Terra, 1986. 171 p.

BRANDÃO, C. R.; BORGES, M. C. A pesquisa participante: um momento da educação popular. Revista de Educação Popular, Uberlândia, v. 6, p. 51-62, jan./dez. 2007.

Disponível em: http://www.seer.ufu.br/index.php/reveducpop/article/view/19988. Acesso em: 22 jul. 2020.

BRASIL. Ministério da Saúde. Conselho Nacional de Saúde. Resolução n. 196, de 10 de outubro de 1996. Aprova as diretrizes e normas regulamentadoras de pesquisas envolvendo seres humanos. Brasília, DF, 16 out. 1996. Disponível em: https://bvsms.saude.gov.br/bvs/saudelegis/cns/1996/res0196 1010 1996.html. Acesso em: 22 jul. 2020.

BRASIL. Ministério da Saúde. Conselho Nacional de Saúde. Resolução n. 466, de 12 de dezembro de 2012. Aprova diretrizes e normas regulamentadoras de pesquisas envolvendo seres humanos. Brasília, DF, 12 dez. 2012. Disponível em: https://bvsms.saude.gov.br/bvs/saudelegis/cns/2013/res0466_12_12_2012.html. Acesso em: 22 jul. 2020.

BRASIL. Conselho Nacional de Saúde. Resolução n. 466, de 12 de dezembro de 2012. Brasília, DF, 2012. Disponível em:

http://bvsms.saude.gov.br/bvs/saudelegis/cns/2013/res0466_12_12_2012.html. Acesso em: 22 jul. 2020.

BRASIL. Ministério da Saúde. Conselho Nacional de Saúde. Resolução n. 510, de 7 de abril de 2016. Trata sobre as diretrizes e normas regulamentadoras de pesquisa em ciências humanas e sociais. Brasília, DF, 24 maio 2016. Disponível em:

https://bvsms.saude.gov.br/bvs/saudelegis/cns/2016/res0510_07_04_2016.html. Acesso em: 22 jul. 2020.

COSTA, F. A.; PRADO, M. A. M. Artimanhas da hegemonia: obstáculos à radicalização da democracia no Brasil. Psicologia \& Sociedade, v. 29, e152680, 2017. DOI: 10.1590/18070310/2017v29152680

FLICK, U. Introdução à pesquisa qualitativa. Trad. Joice Elias Costa. 3. ed. Porto Alegre: Artmed, 2009. 405 p.

GARCIA, R. L. Para quem investigamos - para quem escrevemos: reflexões sobre a responsabilidade social do pesquisador. In: MOREIRA, A. F. et al. Para quem pesquisamos, para quem escrevemos: o impasse dos intelectuais. 2. ed. São Paulo: Cortez, 2003. 
KINCHELOE, J. L.; BERRY, K. S. Pesquisa em educação: conceituando a bricolagem. Trad. Roberto Cataldo Costa. Porto Alegre: Artmed, 2007. 208 p.

KRAMER, S. Autoria e autorização: questões éticas na pesquisa com crianças. Cadernos de Pesquisa, São Paulo, n. 116, p. 51-49, jul. 2002. Disponível em:

http://www.scielo.br/pdf/cp/n116/14398.pdf. Acesso em: 22 jul. 2020.

LOMBARDI, A. R. Construção da Comunidade Escolar: contribuições da Pedagogia do Sujeito Coletivo. 2013. 148 f. Dissertação (Mestrado em Educação) - Universidade da Cidade de São Paulo, São Paulo, 2013.

MEYER, D. E.; PARAIISO, M. A. Metodologias de pesquisas pós-críticas ou Sobre como fazemos nossas investigações. In: MEYER, D. E.; PARAÍSO, M. A. (org.). Metodologias de pesquisas pós-críticas em educação. Belo Horizonte: Mazza Edições, 2012. 308 p.

MINAYO, M. C. S. Ciência, técnica e arte: o desafio da pesquisa social. In: MINAYO, M. C. S. Pesquisa Social: teoria, método e criatividade. Rio de Janeiro: Vozes, 1994.

PARAÍSO, M. A. Metodologias de pesquisas pós-críticas em educação e currículo: trajetórias, pressupostos, procedimentos e estratégias analíticas. In: MEYER, D. E.; PARAÍSO, M. A. (org.). Metodologias de pesquisas pós-críticas em educação. Belo Horizonte: Mazza Edições, 2012. 308 p.

SILVA, O. H. F. Comunidade Escolar: políticas públicas e participação. Unifreire, São Paulo, n. 3, dez. 2015. Disponível em:

http://www.paulofreire.org/images/pdfs/revista_unifreire_3.pdf. Acesso em: 22 jul. 2020.

TEIXEIRA, B. B. Comunidade escolar. In: OLIVEIRA, D. A.; DUARTE, A. M. C.; VIEIRA, L. M. F. Dicionário: trabalho, profissão e condição docente. 2010. Disponível em:http://www.gestrado.org/pdf/374.pdf. Acesso em: 27 ago. 2014.

TEIXEIRA, I. A. C.; PÁDUA K. C. Virtualidades e Alcances da Entrevista Narrativa. In: CONGRESSO INTERNACIONAL SOBRE PESQUISA (AUTO) BIOGRÁFICA, 2 ., Salvador. Anais [...]. Salvador, 2006. CD-ROM.

WELLER, W. Grupos de discussão: aportes teóricos e metodológicos. In: WELLER, W.; PFAFF, N. (org.). Metodologias da pesquisa qualitativa em educação. 3. ed. Rio de Janeiro: Vozes, 2013. 336 p. 


\section{Como referenciar este artigo}

FERREIRA-DA-SILVA, O. H.; SOARES, A. S. Quantos sujeitos devem participar da pesquisa? O sujeito reivindicativo como possibilidade na pesquisa em educação. Revista Ibero-Americana de Estudos em Educação, Araraquara, v. 16, n. 4, p. 2395-2409, out./dez. 2021. e-ISSN: 1982-5587. DOI: https://doi.org/10.21723/riaee.v16i4.14586

Submetido em: 15/07/2021

Revisões requeridas em: 19/08/2021

Aprovado em: 12/09/2021

Publicado em: 21/10/2021 